\title{
Entre territóriose
}

fronteiras: as viagens do

Tenente Blueberrye suas

\section{implicações pedagógicas}

\section{Between territories and frontiers: Lieutenant Blueberry'sjourneys and their pedagogical implications}

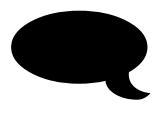

Amaro Xavier Braga Júnior ${ }^{1}$
Universidade Federal de Alagoas e
Thiago Vasconcellos Modenesi ${ }^{2}$
Universidade de Guararapes

Resumo: Enfoca o uso de histórias em quadrinhos no debate de noções históricas acerca dos conflitos entre Estados Unidos da América e México, a instalação da república no México, e geográficas, com a percepção das noções de limite, território e fronteira. Enfatiza como as noções geográficas se constroem em torno de um debate entre natureza e comportamento social, historicamente construído. Toma como base dois álbuns do personagem Tenente Blueberry dos quadrinhos franceses. Metodologicamente, aplica a análise de conteúdo e a crítica hermenêutica para associar imagens e conceitos. Conclui sugerindo que o exercício de leitura e ambientação histórica destas histórias em quadrinhos pode se tornar um importante aliado nas mãos dos professores que estão interessados em desenvolver conhecimentos e habilidades tanto de aspectos geográficos, quanto históricos em seus alunos.

Palavras-chave: Limites. Fronteiras. Ensino de Geografia. História em quadrinhos.

Abstract: Focuses on the use of comics for the discussion of historical notions about the conflicts between United States of America and Mexico, the establishment of Mexican republic, as well as geographic notions, with the perception of the concepts of limit, territory and frontier. Emphasizes how the geographic notions are built around a discussion regarding both the nature and the social behavior, historically built. Takes as its basis two French comics albums of the character Lieutenant Blueberry. Methodologically, it applies the content analysis and the hermeneutic critics to associate images and concepts. Concludes by suggesting that the reading exercise and the historical ambiance of those comics can be important tools in the hands of teachers who are interested in developing geographical and historical knowledge and abilities in their students.
1. Licenciado e Bacharel em Ciências Sociais. Mestre em Antropologia Social. Mestre e Doutor em Sociologia. Professor Adjunto no Instituto de Ciências Sociais da UFAL. amaro@ics.ufal.br.

2. Licenciado em História. Mestre e Doutor em Educação Especialista em Ensino de História. Professor do Mestrado em Inovação e Desenvolvimento (UniFG). Professor Efetivo da UniFG. thiagomodenesi@hotmail. com.

Keywords: Limits. Frontiers. Geographic teaching, Comics. 


\section{Introdução}

As potencialidades pedagógicas das histórias em quadrinhos vêm despertando o interesse de diversos pesquisadores. As incursões são as mais diversas: desde sua defesa, desconstruindo os estereótipos negativos até a implementação de casos concretos (MODENESI; BRAGA JR, 2015a, 2015b, 2016). Quando as histórias em quadrinhos retratam movimentos históricos específicos, é fácil reconhecer sua potencialidade pedagógica. Mas o que temos defendido é que tais incursóes podem ocorrer em diversos momentos distintos, quando o tema da aula não é objeto direto da publicação, mas um pano de fundo das histórias.

Nosso artigo segue este patamar, focando na análise das obras cujo protagonista é o Tenente Blueberry, personagem criado por de Jean Michel Charlier e Jean Giraud. Trata-se de uma série de álbuns de histórias em quadrinhos, publicados originalmente na França, e depois traduzidos para vários países, entre eles o Brasil.

Entre as diversas publicações, analisamos especificamente os álbuns: $\mathrm{O}$ homem que valia $\$ 500.000$ (2008) e Balada para um caixão (2008). Utilizamos alguns parâmetros da análise de conteúdo, de base imagética e organizada de forma ensaística em torno de alguns conceitos, especificamente, os debates amparados em conceitos da geografia e nos Estudos Culturais.

O que exaltamos nesta análise é a relevância e a possiblidade de perceber determinadas dimensões políticas, históricas e geográficas que ambientam os contextos narrativos dos álbuns, por vias de suas imagens desenhadas. Essas histórias do Tenente Blueberry marcam, por exemplo, um momento de conflito entre duas nações por território (Estados Unidos da América e México). Além disso, dentro do México, existe outra perspectiva histórica relacionada às mudanças de regime político, com a superação do colonizador imperialista e a edificação da República.

A noção de território e fronteira são conceitos caros para a geografia e a política. Motivaram diversos conflitos entre as nações e foram reconstituídos pela historiografia enfatizando os motivos e as repercussóes que antecederam e sucederam o determinado movimento. Utilizamos estas duas noções como gatilhos cognitivos e teóricos em um exercício de confronto entre o que diz a teoria e o que se encontra impresso nas imagens dentro dos álbuns em quadrinhos supracitados.

Aqui, seguimos por uma definição de fronteira tanto de propriedade, quanto de integridade de algo, normalmente, associado à vida coletiva de um grupo, e ao espaço de vivência e auto identificação destes em relação aos outros que não habitam a mesma região e, portanto, não compartilham o mesmo ethos identitário. Isto é um elemento definidor da polis do grupo. Antes de tudo, caminhase pelo ideal de separação entre uma coisa e outra, conforme expõe Foucher (1991). Não pretendemos discutir estes conceitos ou problematizá-los, apenas trazê-los para mostrar como se aparentam nas histórias em quadrinhos; busca-se, assim, mostrar como o material desenhado pode ser um recurso didático que auxilia o professor na sala de aula no debate e exemplificação destas categorias.

Uma das dificuldades no ensino de história ou geografia política é ajudar os alunos a entenderem como os contextos territoriais se constroem historicamente. Às vezes, estes contextos são motivados pelas dinâmicas socioculturais da população que habita a região que sofre a mudança e constrói os limites imaginados (ou físicos) do território. Porém, perde-se esta percepção, ao passo que, posteriormente, o território é reivindicado política ou militarmente pela ocupação. Estas histórias em quadrinhos, aqui trazidas, permitem demostrar justamente esta dimensão, de maneira prática, narrativa e natural. Permitem perceber como estas dimensões humanas, microssocializadas, tornam-se agentes dos grandes conflitos políticos que vêm ocupando a pauta da história ocidental. 
Com isso em mente, focamos em apresentar o contexto do álbum e, posteriormente, como as noções de território e fronteira, se vivificam por meio das imagens justapostas destas histórias em quadrinhos, finalizando com o debate histórico e político que elas podem proporcionar na sala de aula.

\section{1 - Os enredos de Blueberry}

Os dois álbuns que aqui analisamos, da série Tenente Blueberry, são O Homem que valia $\$ 500000$ e Balada para um caixão
(Figuras 1e2).Situam-se num determinado corte da história dos Estados Unidos e do México, no século XIX. Obviamente, há uma mistura de realidade com ficção: fatos historicamente conhecidos - macrossociais - são a ambientação dos conflitos microssociais - no qual se envolvem os personagens. Este recurso literário causa um efeito extremamente interessante nas histórias em quadrinhos, ao destacarem importantes referências para entender a geografia, a história e a política e os dois países no qual a trama é ambientada.
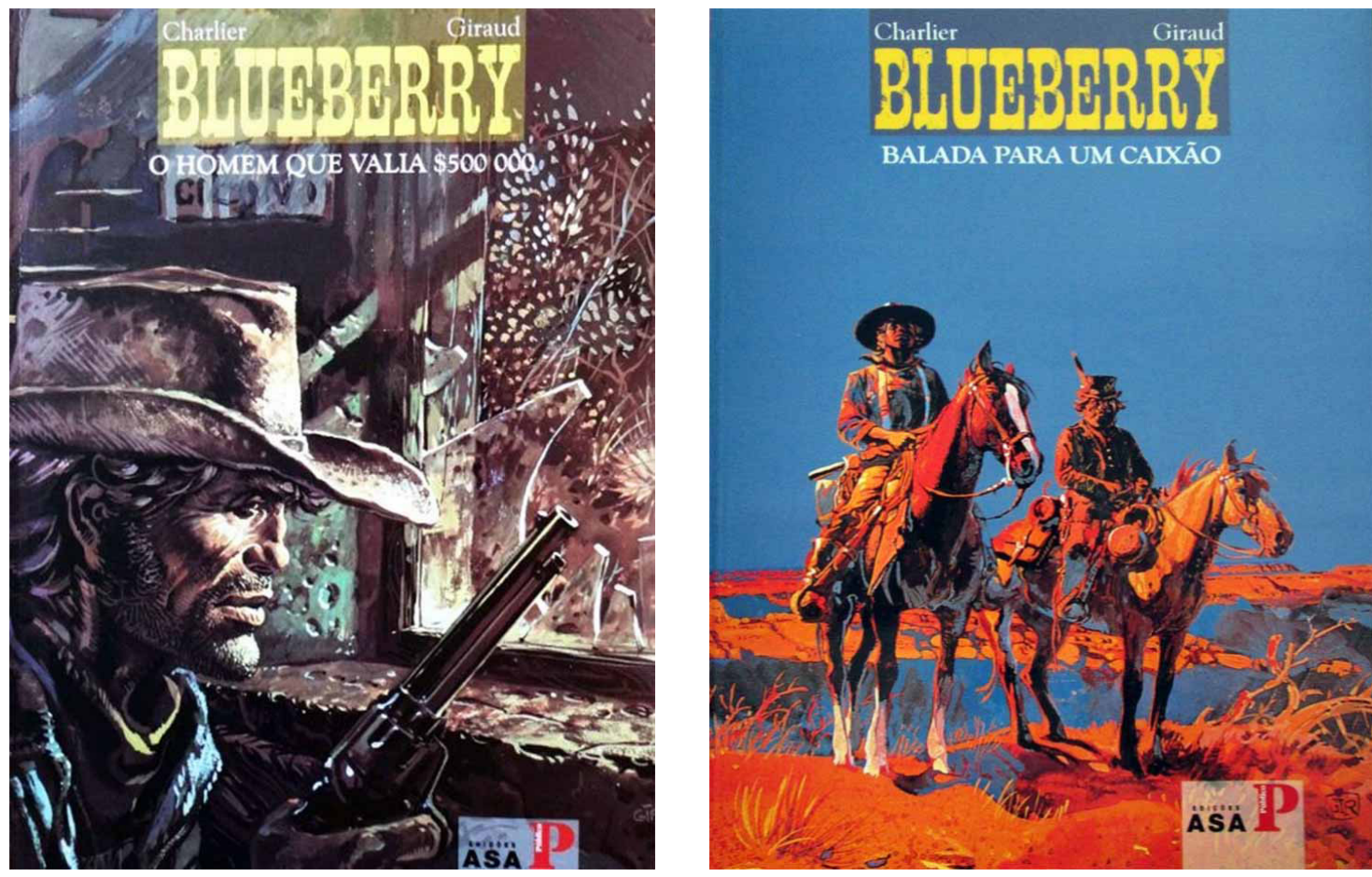

Figuras 1 e 2 - Capas dos álbuns protagonizados pelo Tenente Blueberry. Fonte: Acervo dos autores.

Nessas obras, após a derrota do exército dos confederados na Guerra de Secessão norte-americana (1861-1865), Jefferson Davis, o então presidente do lado confederado, ordenou a Trevor, um de seus soldados mais leais, que se escondesse no México, com seu ouro, para que pudesse vir a reagrupar um exército que tivesse a força suficiente para promover uma volta armada e lutar contra os soldados da União.

Este personagem é um militar com cargo de tenente do exército norte- americano, por isso a alcunha Tenente Blueberry. $\mathrm{O}$ Tenente tem uma conduta pouco ortodoxa e controversa para um protagonista. É afeito a confusões e brigas nos bares. Viciado em jogos de cartas e bebidas alcóolicas. Misógino, machista e sedutor. Um estereótipo de homem másculo, amplamente amparado na filmografia do Oeste Selvagem à moda dos filmes estrelado por Clint Eastwood.

$O$ Tenente se encontra a serviço dos Estados Unidos em território 
mexicano. Sua missão: recuperar o ouro dos confederados. Para este fim, precisa fazer contato com o Trevor, um sulista que foi ao México e lá permaneceu preso. Trevor não quer o ouro para si mesmo como a maioria dos personagens da obra, mantém-se fiel a sua palavra de usar o metal precioso para rearmar os confederados e retomar as hostilidades contra a União. $\mathrm{O}$ ouro foi escondido, secretamente, em um povoado mexicano abandonado. Trevor, posteriormente, foi capturado pelos soldados mexicanos que o perseguiam, já que haviam, no passado, se dedicado ao roubo no território mexicano para poder sobreviver.

O governo vencedor, capitaneado pela União, e conhecedor das histórias sobre este tesouro em ouro, existente em território mexicano, envia o então Tenente Blueberry para localizar Trevor e obrigá-lo, a revelar a localização do ouro.

No enredo geral, temos que tanto as autoridades mexicanas quanto os bandidos americanos terminam tomando conhecimento da existência do tesouro em ouro e entram em conflito na sua disputa.

Finalmente, o Tenente Blueberry consegue contatar Trevor, que estava detido em uma prisão na cidade de Corvado e o ajuda a fugir - graças aos seus contatos junto à mulher conhecida como Chihuahua Pearl, a única mulher com papel importante em toda a história. Trabalha em um cabaré. É casada com Trevor, mas não revela isso a ninguém durante a trama. Apoia-se na sedução para conseguir seus objetivos. Esta sedução, durante as histórias, é tratada como um aspecto de "inteligência" e sempre quando mencionado, causam surpresa nos homens.

Quando chegam a Tacoma, o povoado onde se encontra escondido o tesouro, precisam escapar de um numeroso grupo de soldados mexicanos que os perseguia. Fogem rapidamente rumo à fronteira com os Estados Unidos. Ao fim, descobre-se que o tesouro havia sido descoberto pelas tropas comandadas por
Juárez e, já gasto, havia financiado a revolução contra o imperador Maximiliano. Este fato levará à acusação contra Blueberry de ficar com o ouro quando este já estava no território norte-americano e, como consequência, de ser expulso do exército.

Ainda participam da trama, de forma coadjuvante, dois foragidos norte-americanos: Kimball e Finley, que se colocam na busca da pista do esconderijo do ouro no México. Durante a história se aliam com os mexicanos e com qualquer um dos outros protagonistas para depois os trair e ficar com o ouro. Também, encontramos os companheiros de viagem do Tenente Blueberry: Red Neck e McClure, típica dupla de personagens secundários das histórias em quadrinhos do gênero faroeste. Arruaceiros, com problemas morais e alcoólatras, acompanham fielmente o tenente e não se focam no tesouro que buscam. Por ultimo, destacamos a figura do governador do Estado de Chihuahua, no México, chamado Velasco, que dirige tudo que está ligado ao governo de sua fortalezaprisão, situada em Corvado. Como um bom romance, atua como um antagonista que tanto busca o tesouro quanto a conquista de garota Chihuahua Pearl na história.

\section{2 - Entre imagens e fatos: detalhes histórico-geográficos nas histórias em quadrinhos}

No contexto histórico, diversos elementos se destacam. Não objetivamos findar todos aqui, mas destacar alguns. Por exemplo, foram as tropas francesas que empossaram ou impuseram o Imperador Maximiliano no trono do México; assim como foi republicano Benito Juárez o principal opositor do regime, lutando para derrotar o Império, e que viria a se tornar seu primeiro presidente (KATZ, 1986). Seu principal centro de operaçóes estava em Chihuahua, região onde ocorrem os principais eventos retratados nas histórias em quadrinhos analisadas.

Juárez contava com o apoio dos republicanos e Maximiliano com o dos conservadores, em particular da Igreja 
Católica que chegou a doar dinheiro para a campanha militar. No México, naquele momento, Benito Juárez assumiu o poder após o destronamento e fuzilamento do Imperador Maximiliano, representante do II Império do México. Isso se deu depois do imperador não receber apoio suficiente da França, que estava praticamente em guerra com a Prússia, e com Juárez recuperando o apoio dos Estados Unidos após a vitória da União na Guerra de Secessão (KATZ, 1986).

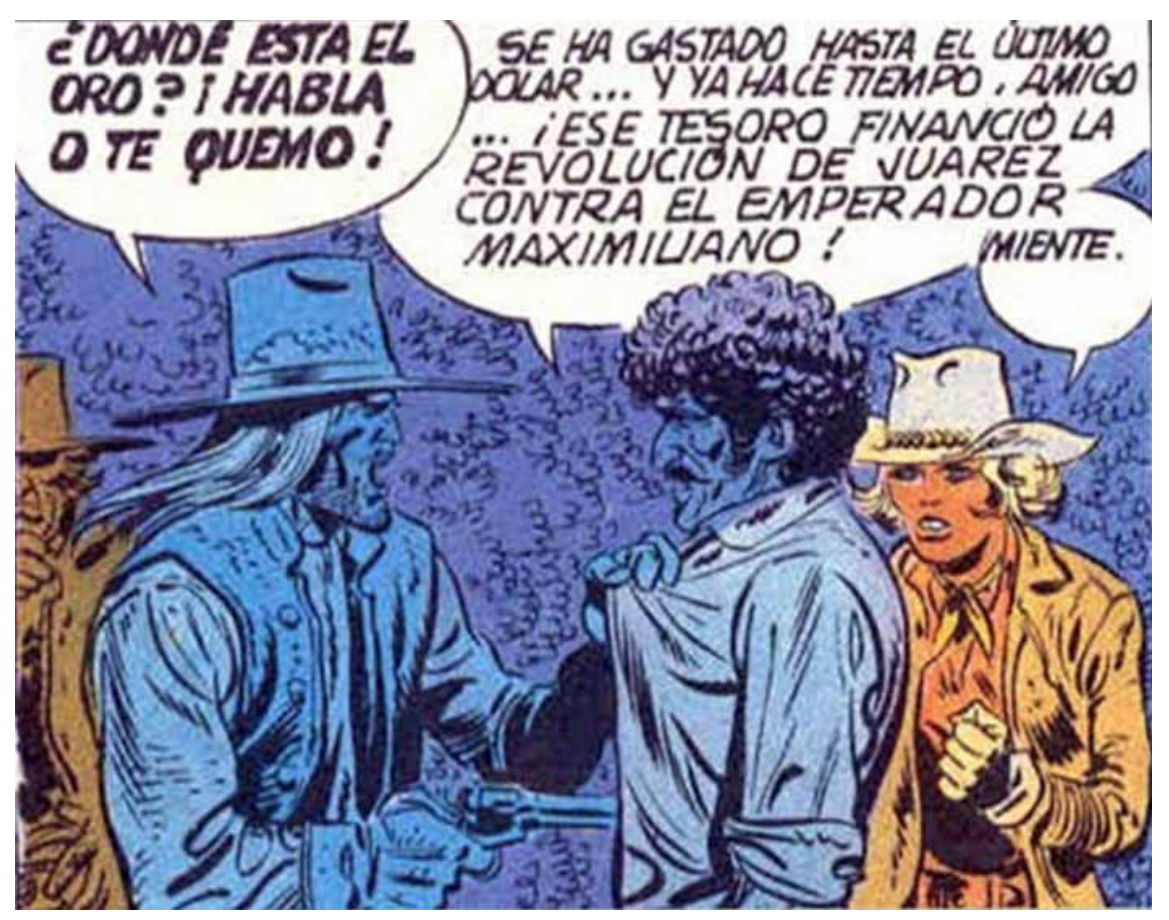

Figura 3 - Na história em quadrinhos se especula que Juarez financiou parte da guerra com o ouro dos confederados até que veio receber financiamento pela União. Fonte: Acervo dos autores.

Este episódio fez com que Juárez fosse visto como libertador. Não era unânime. Ainda teve importantes detratores entre os conservadores, especialmente por sua origem puramente indígena. $\mathrm{O}$ governo dos Estados Unidos apoiava o de Juárez, para expulsar qualquer ingerência europeia na América, sempre no espírito da chamada Doutrina Monroe, que dizia que os Estados Unidos lutariam contra qualquer intervenção europeia no continente americano (KATZ, 1986).

Ao final da Guerra de Secessão, os Estados Unidos estavam devastados, mas dispostos a reconstruir-se e seguir no roteiro da expansão para o oeste, como já haviam feito 20 anos antes, na época também pela costa do México.

Entre 1846 e 1848 ocorreu a Guerra entre o México e os Estados Unidos, o segundo interveio na guerra que o México mantinha junto ao estado do Texas que buscava sua independência, tendo inclusive entrado em combate com as tropas mexicanas. A vitória das tropas norteamericanas, que chegaram inclusive a entrar na Cidade do México, obrigou o presidente Santa Anna a se exilar e o México a firmar o Tratado de Guadalupe-Hidalgo, no qual perdeu territórios enormes para os Estados Unidos (os atuais estados norteamericanos da Califórnia, Nevada, Utah, Novo México e Texas, além de parte do Arizona, Colorado, Wyoming, Kansas e Oklahoma). Além disso, o México viria a renunciar ao território do Texas e a fronteira internacional passaria a ser em Rio Bravo (CAMÍN; MEYER, 2000). 
Nos dias atuais, Juárezé considerado um herói mexicano e da República por expulsar a ingerência europeia e lutar pelos ideais republicanos frente aos imperiais. A ele, foram dedicados alguns dos lugares públicos mais importantes de todas as cidades mexicanas, inclusive uma cidade com o seu nome.

Hoje a fronteira entre os Estados Unidos e o México tem fortes contrastes. Há um grande fluxo migratório para o norte, tanto de mexicanos como de outros povos procedentes da América Central que passam por todo o território mexicano. Esses imigrantes são chamados "costas molhadas", porque cruzam a fronteira pelo Rio Grande. Hoje existe uma vala na fronteira de costa a costa que busca frear o fluxo de imigrantes sem papéis.

A análise que aqui buscamos fazer passa pela mudança de configuração que ocorre lentamente na região com a construção da nação mexicana de tipo republicana a partir do declínio do império nesse país; isso se faz presente, nesse momento histórico, por meio de disputas de territórios, hábitos e referências entre os norte-americanos e os mexicanos na região fronteiriça dos dois países.

Nessas histórias em quadrinhos se pode, facilmente, desenvolver o debate da situação daqueles países, no momento em quesepassaa obraeno seu desenvolvimento posterior. Um como potência mundial (Estados Unidos) e o outro como um país subordinado (México). As narrativas das histórias em quadrinhos transcorrem as situações internas e externas que explicam como e o porquê do México se desenvolver como república e não como um império, ao mesmo tempo em que narra a política expansionista dos Estados Unidos em nível global. Essa política expansionista, ao fim, levará às disputas entre as fronteiras dos Estados Unidos e do México. Também apresentam certas peculiaridades da Guerra de Secessão e, finalmente, da história do México, posterior a sua independência e de perda da metade do seu território no Tratado de Guadalupe-Hidalgo. Transcorrese todo um processo histórico em que estava imerso os Estados Unidos com sua expansão para o Oeste, a posterior Guerra de Secessão e as relações conturbadas com o México e o início da conformação dos EUA como uma potência mundial. Neste ínterim, ainda é possível, destacar, a importância do ouro em um momento em que a economia mundial estava baseada no chamado "padrão-ouro". (CAMÍN; MEYER, 2000)

Destes contextos históricos partimos para os geográficos. As atuais fronteiras entre México e Estados Unidos foram fixadas no Tratado de Guadalupe-Hidalgo depois que os EUA derrotaram os mexicanos na guerra. A fronteira tem uma longitude de 3.185 $\mathrm{km}$ - uma das fronteiras mais extensas do mundo, atravessando três grandes zonas geográficas de Leste a Oeste: o Rio Grande que serve de fronteira, o Deserto de Chihuahua e o Deserto de Sonora. No enredo das histórias é possível perceber múltiplas situações de como se dá a relação humana, nativa e visitante, no enfretamento das dificuldades impostas pelo deserto de Chihuahua e da paisagem da região (KATZ, 1986).

É exatamente nessa região que se desenvolve praticamente toda a trama da história. Além disso, Chihuahua foi de importância vital para a sublevação de Juarez contra o Imperador Maximiliano. $\mathrm{O}$ deserto de Chihuahua possui em torno de $450.000 \mathrm{~km}^{2}$ e se estende pelo território de ambos os países. Consiste, principalmente, de vales separados por várias cordilheiras de pequena estatura. Estes vales formam microclimas mais frescos e úmidos que podem acolher importantes massas de vegetação (KATZ, 1986). 


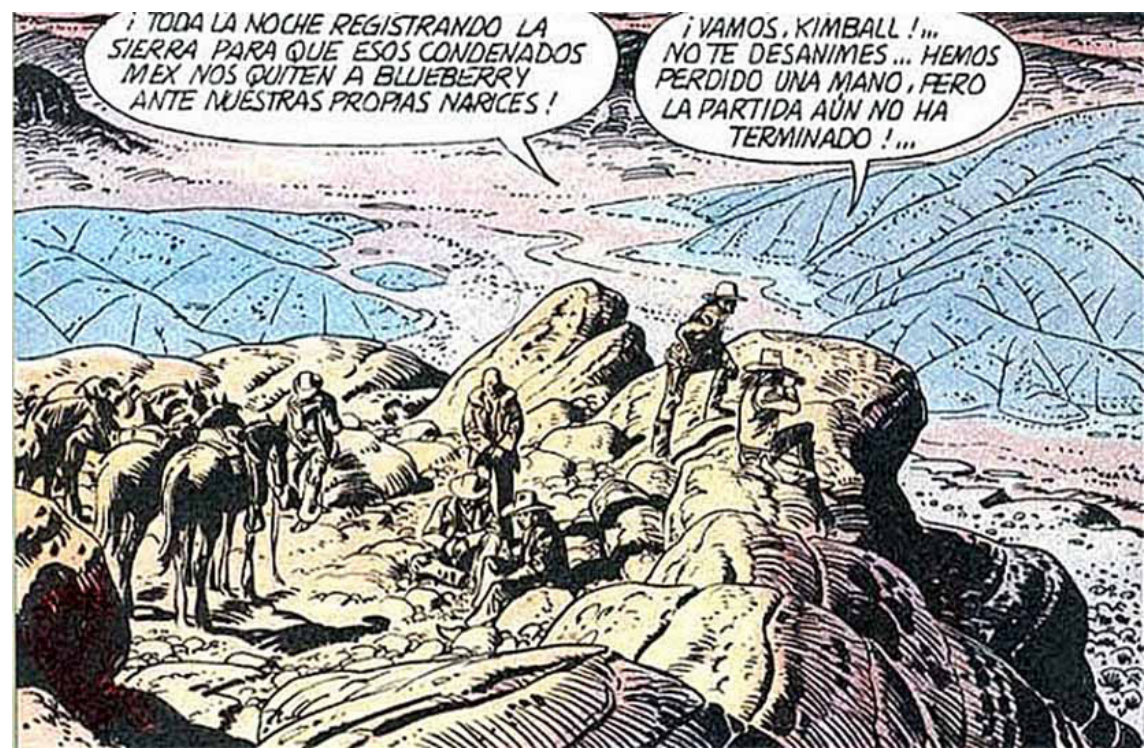

Figura 4 - Cena retratando o deserto de Chihuahua e os diversos vales que ele tem.

Fonte: Acervo dos autores.

Este deserto apresenta uma altitude que varia entre os 600 e os 1.675 metros acima do nível do mar. As temperaturas variam entre os 35 e 40 graus durante o dia, mas não é considerado entre os mais quentes do mundo. $\mathrm{O}$ deserto possui uma flora de matagais e pastagens e uma fauna abundante, alguns de seus animais mais típicos são o coelho do deserto, a lebre da Califórnia e a raposa veloz, há ainda a cascavel de Mojave e o bisonte americano (KATZ, 1986). Na capa do álbum Balada para um Caixão, é possível, inclusive, ver alguns detalhes da flora e do tipo desértico da região do México em que se passa a história.

Não vamos desgastar toda a representação da natureza presente nesses quadrinhos. Deixamos a sugestão ao professor para que se guie na identificação destes elementos a partir das pistas e apontamentos iniciais que propusemos. Adiante, problematizamos alguns aspectos relevantes neste diálogo entre a teoria sobre determinados fenômenos geográficos e a tessitura das imagens dos quadrinhos.

Como bem se sabe, a noção de fronteira é impactante para pensamento social. Ela é tanto instigadora da ideia abstrata de nação, povo e território, quanto definidora das percepçóes concretas de elementos físicos, geográficos, climáticos e ambientais - e acima de tudo, étnicos, que delimitam os mesmos conceitos.

Este tipo de embate nos permite traçar uma relação entre a noção geográfica e a percepção etnográfica. As histórias em quadrinhos permitem confrontar, ao mesmo tempo, as duas noções. Temos a narrativa, tanto descritiva, quanto visual. Esta, corrobora para perceber como os parâmetros fronteiriços se desenvolvem numa cultura ou Estado-Nação, sempre por meios de lutas, conflitos e confrontos interculturais, motivados, sobretudo, por interesses econômicos relacionados à sobrevivência de um grupo em detrimento do outro.

Percebe-se também, como apontam os estudos teóricos sobre as fronteiras (MARTIN, 1997; RAFFESTIN, 1993), o papel que as "fronteiras naturais" exercem na percepção da população do limite territorial de um grupo e de outro. Ou ainda, como a ambientação destes cenários fronteiriços, sejam políticos ou naturais, estão a serviço da dominação. Afinal, é o que os enredos de Tenente Blueberry demonstram claramente, mesmo sem nominar ou apontar de maneira explícita 
e cujo conteúdo crítico e perceptivo pode ser apontado pelo professor ao aluno leitor do material como resultante de uma leitura crítica e perceptiva sobre os processos históricos e historiográficos que criam as fronteiras entre os países, deixando óbvio, como aponta Foucher (1991), que todas as fronteiras lineares são construções humanas guiadas por objetivos também humanos, fortemente relacionados à dominação (política, cultural, econômica...).

Neste tipo de enredo também é possível perceber a ideia de fronteira conforme defende Frederick Turner (KNAUSS, 2004; MARTIN, 1997). Não à toa, ambos, as histórias em quadrinhos e o historiador, se ambientam no mesmo espaço: o oeste estadunidense. Nesta perceptiva, fronteira territorial e identidade se auto gestionam mutuamente num processo contínuo de inter-relação e dependência.

Nesta lógica, a própria ideia de limite também se insere. No enredo, as concepções de fronteira e limite se chocam conforme as crises dos personagens se apresentam no desenvolvimento da história a partir de quando os conflitos sociais são apresentados aos leitores. Às vezes, o início e o fim do controle político-territorial são conhecidos e, outras vezes, ignorados ou relembrados pelos personagens nas histórias destas histórias em quadrinhos. Desta forma, temos uma narrativa - às vezes, descritiva imageticamente, outras, textualmente, outras ainda, a partir da situação e ambientação dos personagens em cena (à moda da crítica literária ao analisar o mise en scène). Exemplifica-se, assim, como a noção de limite se apresenta em conflito com a de fronteira. A tensão social na qual o Tenente Blueberry se depara, mobiliza/caracteriza/vivifica, justamente, a ambientação antagônica entre "forças centrífugas" (as fronteiras) e as "forças centrípetas" (os limites) como esclarece Machado (1998).

Por meio do enredo dessas histórias preserva-se, claramente, a diferença entre estas noções geográficas. Pelo enredo dos acontecimentos é possível compreender como "enquanto o limite é criado pelo poder para controlar e regular atividades e interações, a fronteira pode ser concebida como espaço de construção social", conforme definição teórica apresentada por Ferrari (2014, p.22).

Retomando: é neste sentido, que o enredo destas histórias em quadrinhos nos faz perceber todo um debate sobre a noção de fronteira:

A fronteira possui duas visões cientificas: uma que trata $\mathrm{da}$ história política entre Estados nacionais e do limite de soberania de um poder central e a outra local ou regional que trata do vivido e das interações entre populações em zonas fronteiriças. Nessas duas visões, fronteira se inscreve hoje dentro de uma ampla problemática tornando se objeto de pesquisas cientificas, com inúmeras possibilidades de estudos, mas a tendência atual parece apontar para um contexto mais humano, social e cultural capaz de nos oferecer uma apreensão mais justa e real das relações fronteiriças. (FERRARI, 2014, p.23).

As viagens dos protagonistas do álbum permitem ao leitor viajar sobre a dinâmica histórica de formação dos Estados Unidos e do México em seus processos desiguais de constituição em estadosnação. Os enredos das revistas colocam uma dimensão que é imaginada (e, ao que parece, defendida pelos autores) pelo qual as fronteiras políticas e culturais não são claras ou perceptíveis. Há um forte discurso de civilização, muito associado à ideia de ordem e progresso, colono e colonizador, justiça e barbárie. Uma dualidade com forte discurso civilizatório que se apresenta em duas dimensões.

A primeira dimensão é temática. 
A história retratada é a aquela imaginada e narrada pelos livros de história ou que antevê discursos e problemas geopolíticos. O roteirista dos álbuns, Jean-Michel Charlier, foi um belga que nunca visitou o México ou as regióes de fronteira descritas na história, mas que tinha uma assinatura temática fortemente associada ao retrato de conflitos territoriais em seus roteiros. $\mathrm{Da}$ mesma forma, o desenhista, Jean Giraud, nunca esteve na região e, devido a seu serviço militar compulsório na Argélia, desenvolveu uma posição política avessa ao debate destas instâncias (o que se reflete na continuidade do álbum, após a morte de Jean-Michel, onde o protagonista das histórias não circula mais pelas regiôes fronteiriças e vive "cansado" em uma cidade imaginada na região).

Nesta dimensão, supracitada, o trânsito dos personagens é uma viagem pela história dos conflitos políticos da região. É possível seguir todo o processo de desterritorialização (GARCÍA CANCLINI, 2010) que acomete a identidade do indivíduo que não pertence a uma região - delimitada politicamente mas, às instâncias da paisagem do lugar $e$ de suas aventuranças transterritoriais. JeanMichel Charlier nos apresenta um debate, amparado na ficção histórica, sobre as dinâmicas da globalização e seu impacto na formação das paisagens territoriais. É um processo de socialização - mediado pela publicação de material artístico-midiático (história em quadrinhos) - pelo qual se condiciona uma mudança de pensamento dos indivíduos em torno do processo, neste caso, civilizador, tal como descrito pelo sociólogo Norbert Elias (1993; 2000).

Essa mesma situação é passível de compreensão a partir de um exemplo que seja mais fácil de ser compreensiva pelos brasileiros, pelo álbum Caatinga de Hermann Huppen (1998), outro belga que nunca esteve no sertão brasileiro, mas reproduziu no álbum em quadrinhos uma série de paisagens, fauna e flora que (re)construíam este imaginário sobre os elementos - físicos e sociais - que compunham o cenário. É possível, numa comparação cruzada dos dois álbuns, inclusive, perceber como os cenários das paisagens são extremamente semelhantes não só na definição visual do território, mas da própria construção do biótipo dos indivíduos que muito se assemelham quanto ao formato do rosto e posição corporal. Uma clara associação com os desenhos de faroeste ao qual desenhistas e leitores já haviam se acostumado a produzir na Europa.

É neste momento que adentramos na segunda dimensão. Uma dimensão estética. A arte do álbum transcorre por regióes e paisagens - imaginadas - de um Oeste padrão, às vezes estéril e outras, florido em oásis bucólicos, completamente fantasiosos. O cenário retratado é constituído a partir de fotografias de região, mas, ficcional, que - ao contrário do que se poderia supor passa a ganhar status de real para os leitores do material. Passam a representar uma "viagem" ao local. Por eles, conhecemos uma flora e fauna imaginada e sorvemos a bucólica configuração da paisagem. Novamente, temos neste processo de construção - que não é exclusivo do modelo da bande dessinée - a história em quadrinhos servindo como agente de "simulação de sujeitos" (GARCÍA CANCLINI, 2009). A grande questão é que há um pacto de confiança entre o leitor que não apenas de se entreter com a leitura, mas se informar, através dela. Obviamente, pela própria dinâmica que se processa estes álbuns em quadrinhos que narram viagens, cenários e paisagens, constroem e edificam territórios (geográficos ou políticos) precisam, sobremaneira, se guiar pela dinâmica do estereótipo.

\section{Considerações finais}

$O$ processo de figuração das paisagens descritas\desenhadas nos álbuns de Blueberry aqui analisados permite que o leitor possa refletir sobre aspectos tanto político-históricos, quanto artístico- 
estéticos em torno das definições do que é local, nacional e transnacional. Dos limites e do território. Da própria percepção do que é paisagem. E, principalmente, o papel das pessoas - do social - na construção dos aspectos geográficos e ambientais.

Trata-se de um exercício de reflexão, análise e leitura crítica, para identificar como estes parâmetros aparecem na história e condicionam as explicações historiográficas sobre os acontecimentos políticos, a delimitação das fronteiras geográficas, políticas e culturais entre os dois países e o papel que o ouro desempenhava na mudança de status destas relaçóes naquele dado período histórico.

$\mathrm{O}$ que estas histórias em quadrinhos podem proporcionar - além de entretenimento - é a observância de como a dinâmica dos acontecimentos históricos e sociais se coaduna, implicando em mudanças geopolíticas que demarcam os territórios das nações e dos povos na sociedade contemporânea.

O exercício de leitura e ambientação histórica dessas narrativas quadrinísticas pode se tornar um importante aliado nas mãos dos professores que estão interessados em desenvolver estes conhecimentos e habilidades em seus alunos.

\section{Referências}

CAMÍN, Héctor Aguilar; MEYER, Lorenzo. À sombra da revolução mexicana: história mexicana contemporânea, 19101989. São Paulo: EDUSP, 2000. CHARLIER, Jean-Michel; GIRAUD, Jean. Balada para um caixão. Lisboa: Asa, 2008.

O Homem que valia $\$ 500000$.

Lisboa: Asa, 2008.

ELIAS, Norbert. O processo civilizador. Rio de Janeiro: Jorge Zahar. Ed., 1993.

Os estabelecidos $e$ os outsiders: sociologia das relaçóes de poder de uma pequena comunidade. Rio de Janeiro: Jorge Zahar Ed, 2000.

FERRARI, Maristela. As noções de fronteira em geografia. Revista Perspectiva
Geográfica, Marechal Cândido Rondon, PR, UNIOESTE, v.9, n. 10, 2014. Disponível em: http://e-revista.unioeste.br/index. $\mathrm{php} /$ pgeografica/article/view/10161/7550. Acesso em 10 out. 2019.

FOUCHER, Michel. Fronts et frontiers: un tour du monde géopolitique. Paris: Fayard, 1991.

GARCÍA CANCLINI, Nestor. Consumidores e cidadãos: conflitos multiculturais da globalização. Rio de Janeiro: Editora UFRJ, 2010.

Diferentes, desiguais e

desconectados: mapas de interculturalidade. Rio de Janeiro: Editora UFRJ, 2009.

HUPPEN, Hermann. Caatinga. Rio de Janeiro: Globo, 1998.

KATZ, Friedrich. Revuelta y revolución: la lucha rural en México del siglo XVI al siglo XX. Ciudad del Mexico: Ediciones Era, 1986. 2v.

KNAUSS, Paulo (org.). O Oeste americano: quatro ensaios de história dos Estados Unidos da América de Frederick Jackson Turner. Niterói: EdUFF, 2004.

MACHADO, Lia Osório. Limites, fronteiras, redes. In: STROHAECKER, Tânia Marques. et al. (org.). Fronteiras e espaço global. Porto Alegre: AGB - Seção Porto Alegre, 1998.

MARTIN, André Roberto. Fronteiras e nações. São Paulo: Contexto, 1997.

MODENESI, Thiago Vasconcellos; BRAGA JR, Amaro Xavier. Quadrinhos E Educação, vol.1: relatos de experiência e análises de publicações. Jaboatão dos Guararapes: Faculdade dos Guararapes, 2015a.

Quadrinhos E Educação, vol.2:

Procedimentos Didáticos. Jaboatão dos Guararapes: Faculdade dos Guararapes, $2015 b$.

Quadrinhos E Educação, vol.3: fanzines e usos pedagógicos. Jaboatão dos Guararapes: Faculdade dos Guararapes, 2016.

RAFFESTIN, Claude. Por uma geografia do poder. São Paulo: Ática, 1993. 